\title{
Red dichromatic imaging helps in detecting exposed blood vessels in gastric ulcer induced by endoscopic submucosal dissection
}

Delayed bleeding is one of the postoperative complications of gastric endoscopic submucosal dissection (ESD) [1]. The clipping of exposed blood vessels after ESD completion is effective in preventing delayed bleeding [2,3]. However, the exposed blood vessels are sometimes difficult to detect. Herein we report the effectiveness of a novel image-enhanced endoscopic technology called red dichromatic imaging (or dual red imaging) for detecting exposed blood vessels and preventing delayed bleeding after gastric ESD.

A 61-year-old man had a 25-mm 0-Ilc lesion located in the middle gastric body. We performed ESD using esophagogastroduodenoscopy (GIF-H290T with EVIS X1 video system; Olympus Medical Systems, Tokyo, Japan). After completion of ESD, the scope was changed to a GIF-EZ1500, and the ESD-induced ulcer was observed ( $>$ Fig. 1 a, \Video 1). We switched the white light imaging to red dichromatic imaging and the exposed blood vessels were more clearly visualized ( $>$ Fig. 1 b, $\triangleright$ Video 1). A blood vessel penetrating the muscle layer was covered with submucosal fibrous and fatty tissue, as observed by white light (>Fig.2a). This blood vessel could be identified more clearly than the surrounding tissue using red dichromatic imaging ( $\mathbf{F i g . 2} \mathbf{b}$ ). We were able to easily detect the exposed blood vessels using red dichromatic imaging and then perform clipping (HX-610-090S; Olympus Medical Systems) ( Fig.3). The patient was discharged without delayed bleeding.

Red dichromatic imaging is a novel image-enhanced endoscopic technology using three wavelengths $(540 \mathrm{~nm}$, $600 \mathrm{~nm}$, and $630 \mathrm{~nm})$. Its effectiveness for detecting bleeding vessels has been previously reported [4]. In this case, submucosal fibrous tissue, fatty tissue, and the muscle layer were identified as a whiter collar using red dichromatic ima-
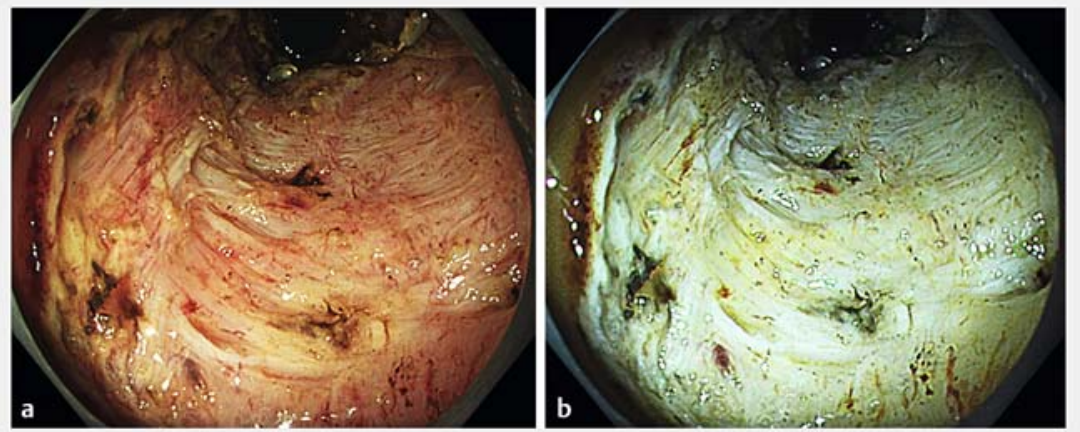

- Fig. 1 Endoscopic submucosal dissection (ESD)-induced ulcer. a Observed using white light. b Observed using red dichromatic imaging.

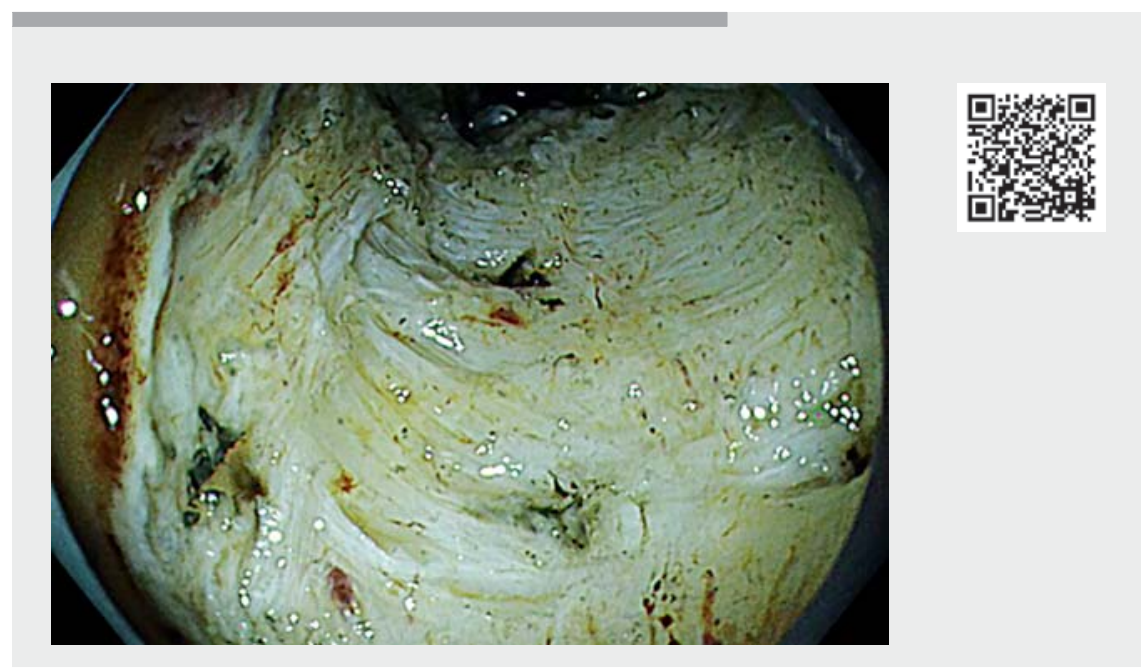

Video 1 The observation of the exposed blood vessels in a gastric ulcer induced by endoscopic submucosal dissection using red dichromatic imaging.

ging rather than white light. Red dichromatic imaging helped gain a clear endoscopic view during colorectal ESD with submucosal fatty tissue [5]. We were able to easily detect the exposed blood vessels using red dichromatic imaging because the color difference between the exposed blood vessels and surrounding tissue was clear.

Endoscopy_UCTN_Code_TTT_1AO_2AB

\section{Competing interests}

The authors declare that they have no conflict of interest. 

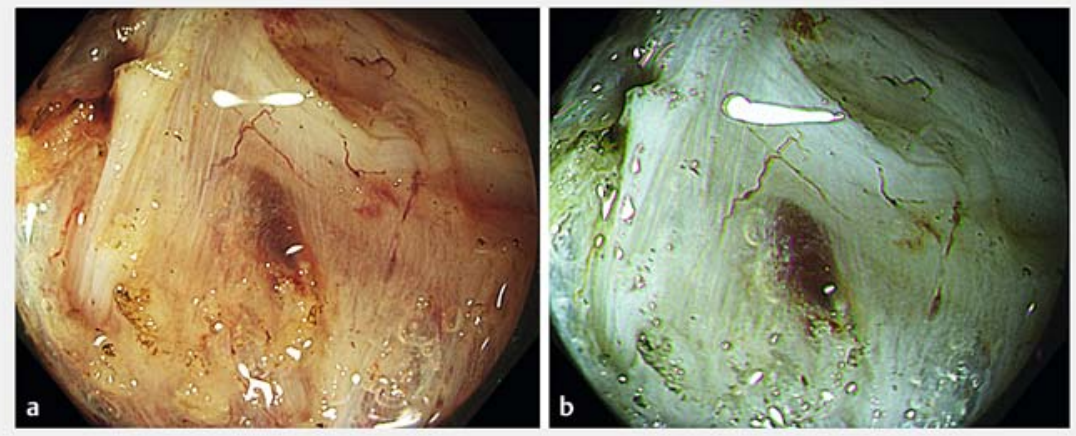

- Fig. 2 a The blood vessel penetrating the muscle layer was covered with submucosal and fatty tissue, as observed by white light. $\mathbf{b}$ The blood vessel could be identified more clearly than the surrounding tissue using red dichromatic imaging.

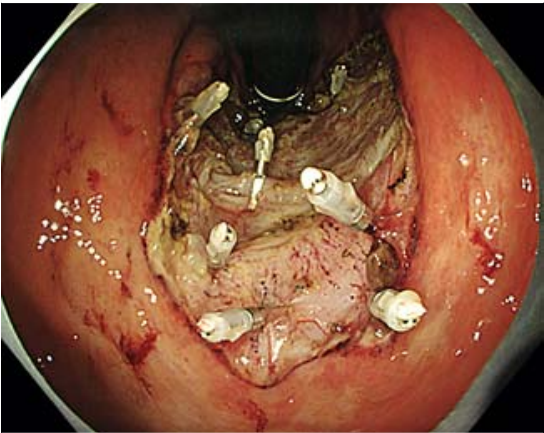

Fig. 3 Endoscopic submucosal dissection-induced ulcer after clipping.

Bibliography

Endoscopy 2021; 53: E403-E404

DOI $10.1055 / \mathrm{a}-1314-9714$

ISSN 0013-726X

published online 17.12 .2020

(c) 2020. Thieme. All rights reserved.

Georg Thieme Verlag KG, Rüdigerstraße 14,

70469 Stuttgart, Germany

rection to: The search, coagulation, and clipping (SCC) method prevents delayed bleeding after gastric endoscopic submucosal dissection. Gastric Cancer 2019; 22: 576

[3] Mukai S, Cho S, Nakamura S et al. Postprocedural combined treatment using the coagulation plus artery-selective clipping (2C) method for the prevention of delayed bleeding after ESD. Surg Endosc 2013; 27: 1292-1301

[4] Fujimoto A, Saito $Y$, Abe $S$ et al. Haemostasis treatment using dual red imaging during endoscopic submucosal dissection: a multicentre, open-label, randomised controlled trial. BMJ Open Gastroenterol 2019; 6: e000275

[5] Tanaka H, Oka S, Tanaka S et al. Dual red imaging maintains clear visibility during colorectal endoscopic submucosal dissection. Dig Dis Sci 2019; 64: 224-231 